\title{
The Sibbald Library Engraving Collection
}
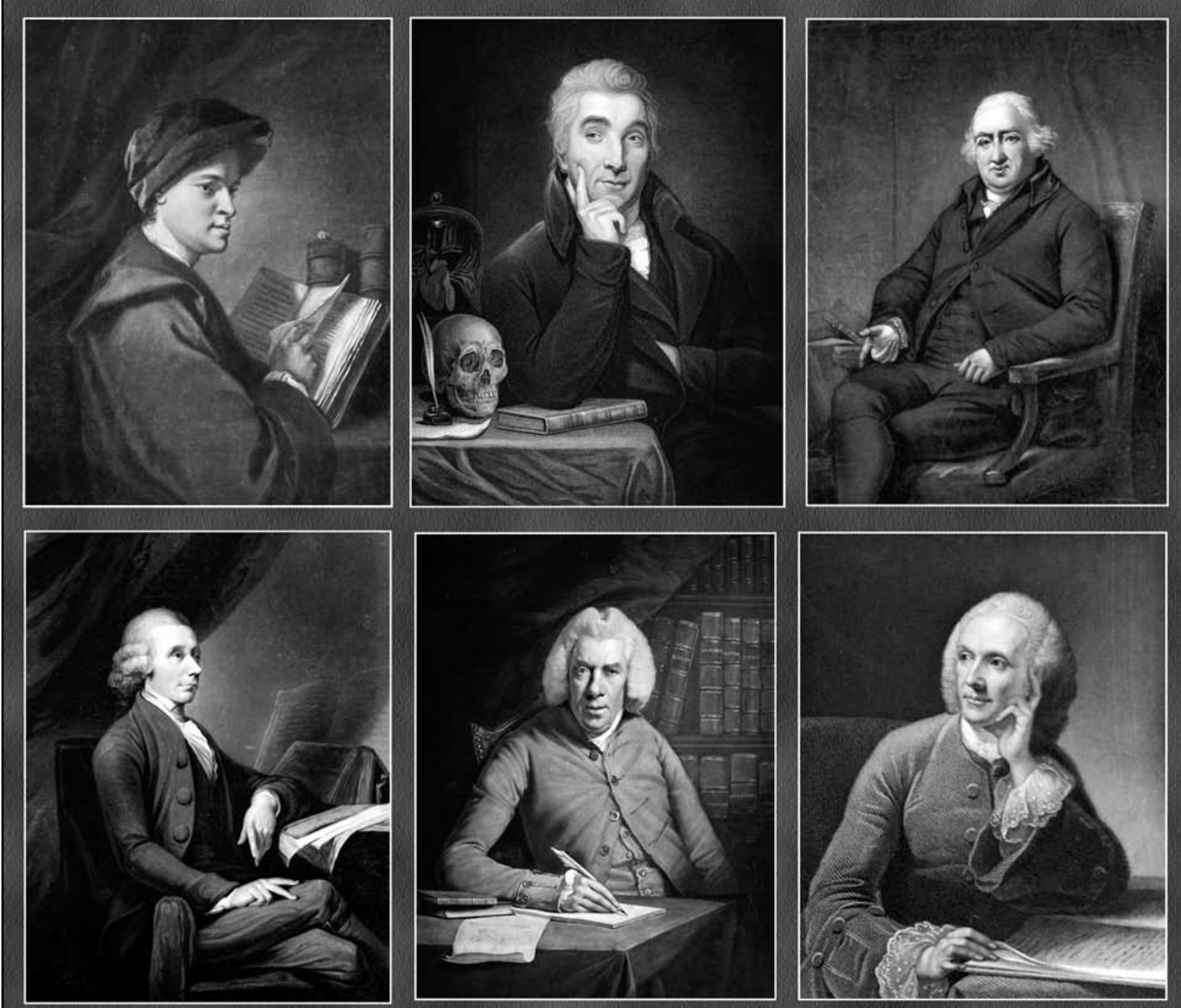

Illustrated clockwise from top left: John Mudge (172I-1793), John Haighton (1755-1823), Erasmus Darwin (I73I-I802), Dr Frankland (date unknown), Henry Harington (1727-1816) and William Hunter (I7| 18-1783).

Visitors to the College often admire the framed engravings on the walls of the corridor leading to the New Library, but few are aware of the six-volume collection of 652 prints compiled by the College in the nineteenth century. Most of the prints are early modern engraved portraits of medical practitioners and you can visually trace the evolution of medical professionalism through the collection.

Many of the engraved portraits include specific objects and visual references that relate to the careers of the depicted medical practitioners. The most common props are books, papers and writing implements.
Popular compositions show the sitter in a domestic context, often seated in an armchair or standing next to a writing desk.

Plainness, modesty and simplicity were desirable in an ideal doctor and these qualities were emphasised by dress. The unadorned uniform black suit came to symbolise the serious professional man rather than official costume or elaborate finery.

By the start of the nineteenth century public service began to be emphasised. Service to hospitals, medical institutions, the crown and the army were all celebrated. These prints were often used as a way to create a public reputation for the sitter, in their lifetime or posthumously.

Earlier this year Charlotte Brown worked on the collection as part of a MSc in History at the University of Edinburgh focusing on eighteenth-century material and visual culture. The College website now contains a selection of these portraits accompanied by a brief description with an emphasis on the artistic representation of the medical profession:

http://www.rcpe.ac.uk/library/ exhibitions/engravings/index.php

lain Milne Sibbald Librarian, RCPE 